\title{
A content analysis of children's television advertising: focus on food and oral health
}

\author{
Maria Morgan ${ }^{1, *}$, Ruth Fairchild ${ }^{2}$, Andrea Phillips ${ }^{1}$, Kate Stewart ${ }^{3}$ and Lindsay Hunter ${ }^{1}$ \\ ${ }^{1}$ Applied Clinical Research and Public Health Group, Cardiff University School of Dentistry, Heath Park, Cardiff \\ CF14 4XY, UK: ${ }^{2}$ Food Research and Consultancy Unit, Cardiff School of Health Sciences, UWIC, Western \\ Avenue, Llandaff, Cardiff CF5 2YB, UK: ${ }^{3}$ Academic Unit of Primary Health Care, University of Bristol, \\ 25 Belgrave Road, Bristol BS8 2AA, UK
}

Submitted 30 July 2007: Accepted 2 May 2008: First published online 1 August 2008

\begin{abstract}
Objectives: To analyse the nature and content of advertising during children's popular television viewing times with the specific aims of (i) identifying the proportion of advertising time devoted to confectionery and potentially cariogenic products (those which readily give rise to dental caries, more commonly known as tooth decay); and (ii) determining whether there is a variation in the advertisement of confectionery and other high-sugar products within children's school holiday time $v$. outside holiday time.

Method: In five separate one-week periods, the output of the four most popular British children's commercial television channels was video-recorded during the most popular viewing times for children. In total, $503 \mathrm{~h}$ of television were recorded and analysed.

Results: Analysis of the recordings revealed that $16 \cdot 4 \%$ of advertising time was devoted to food products; $6 \cdot 3 \%$ of all advertising time was devoted to potentially cariogenic products. Sugared cereals were the most commonly advertised highsugar product, followed by sweetened dairy products and confectionery $\left(\chi^{2}=6524 \cdot 8, \mathrm{df}=4, P<0 \cdot 001\right)$. The advertisement of confectionery and highsugar foods appeared to be influenced by school holidays.

Conclusions: Health-care professionals should be aware of the shift away from the advertisement of confectionery towards the promotion of foods that might be considered healthier but contain large amounts of hidden sugar.
\end{abstract}

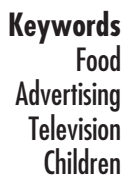

Dental caries and obesity both constitute a significant public health problem in the $\mathrm{UK}^{(1-3)}$ and worldwide ${ }^{(4)}$. There is mounting evidence that obesity and dental caries are linked $^{(5)}$ and both are related to poor food selection behaviour. Furthermore, all three of these factors are more prevalent within lower socio-economic groups ${ }^{(6-8)}$.

In 2006, $40 \%$ of British 5-year-olds had experience of dental caries and these children had an average of 1.6 affected (i.e. decayed, missing or filled) teeth. There is a considerable range of caries experience, with 21\% of 5-year-olds in Mid Essex Primary Care Trust in England having at least one tooth affected by caries compared with $76 \%$ in Merthyr Tydfil Local Health Board in Wales ${ }^{(2)}$.

Obesity, especially in children, is increasing dramatically across the UK. Jebb et $a l^{(3)}$ reported that $4.0 \%$ of British children aged 4-18 years were obese, with a further $15 \cdot 4 \%$ identified as overweight. Increasing obesity levels in children are closely linked to type 2 diabetes mellitus and metabolic syndrome in adults ${ }^{(9)}$, which has major implications for life expectancy, quality of life and scarce health resources.
There is an irrefutable association between sugar intake and tooth decay ${ }^{(10)}$. In addition, the association between the consumption of energy-dense foods, which the UK Food Standards Agency (FSA) defines as foods high in fat, sugar and salt (HFSS) ${ }^{(11)}$, and obesity has been established $^{(12)}$.

Children are particularly vulnerable to sophisticated television advertising promoting HFSS foods including confectionery $^{(13)}$. The food industry views children as an important market because of their tremendous spending power and influence over parents' income ${ }^{(14)}$. In the UK, a systematic review of the effects of food advertising, primarily television advertising, concluded that food promotion was having an effect particularly on children's preferences, purchase behaviour and consumption. Furthermore, the effect was independent of other factors and operated at both brand and category level ${ }^{(15,16)}$. Children who are heavy television users have been shown to be more likely to ask for advertised products ${ }^{(17)}$, which are predominantly HFSS foods ${ }^{(18)}$, and also have unhealthy conceptions about food ${ }^{(19)}$. 
In the 1950s and 1960s the total volume of children's programming broadcast on British television was less than $1000 \mathrm{~h}$ per annum; this soared to $113000 \mathrm{~h}$ in 2006 , due to the proliferation of dedicated children's channels ${ }^{(20)}$.

Traditionally, British children's 'prime time' viewing has been 15.15 to 17.00 hours on weekdays, 06.00 to 13.00 hours on Saturdays and 06.00 to 11.00 hours on Sundays. However, these viewing patterns are changing, not least because almost two-thirds of British children now have a television set in their bedroom, which allows unsupervised television viewing ${ }^{(21)}$. Indeed, in 2003, the top twenty programmes watched by children were broadcast primarily outside children's airtime, with Eastenders and Coronation Street (soap operas), Comic Relief (charity event) and Pop Idol (entertainment programme) being the top four ${ }^{(22)}$. British children aged between 4 and 15 years watch television for an average of $17 \mathrm{~h} /$ week, $12 \mathrm{~h}(70 \%)$ of which are outside traditional children's viewing hours. Of the average total viewing time, only $2 \cdot 6 \mathrm{~h}(15 \cdot 3 \%)$ is spent in commercial children's airtime $^{(22)}$. Furthermore, children in the lowest social class groups, who are at greater risk of developing dental caries and obesity ${ }^{(6,7,23)}$, watch more television than children in higher social classes ${ }^{(22)}$.

In the UK, television advertising is regulated by the Office of Communications (Ofcom), the independent regulator and competition authority for the UK communications industries. In February 2007, Ofcom published its final statement on the advertising of food and drink products to children ${ }^{(24)}$. Key measures included the following:

1. Scheduling restrictions applied to food and drink products assessed as HFSS as defined by the FSA's nutrient profiling model;

2. A total ban on HFSS food and drink advertisements in and around all programmes of particular appeal to children under 16 years old from 1 January 2008 (and from programmes of particular appeal to children under 10 years old from 1 April 2007);

3. A total ban on HFSS food and drink advertisements in and around all children's programming, and on dedicated children's channels as well as in youth-oriented and adult programmes which attract a significantly higher than average proportion of viewers under the age of 16 .

In addition to the scheduling restrictions outlined above, content rules also apply to all food and drink advertising to children, irrespective of when it is scheduled. These rules include banning the use of celebrities and characters licensed from third parties, promotional offers and health claims in HFSS product advertisements aimed at primary-school children or younger. All restrictions on product advertising apply equally to product sponsorship and Ofcom will review the effectiveness and scope of new restrictions in autumn 2008, one year after the full implementation of the new content rules.
Conducted in the six months immediately prior to the introduction of the above measures, the present study aimed to:

1. Examine the nature and content of television advertising on commercial terrestrial and non-terrestrial channels during children's popular television viewing times, with specific reference to oral health;

2. Identify the proportion of advertising aimed at the marketing of confectionery and other cariogenic food/ drink products;

3. Determine the extent to which television advertising changes during school holiday and non-holiday periods.

\section{Method}

The weekly viewing summary produced by the Broadcasters' Audience Research Board (BARB) for the week ending 24 September $2006^{(25)}$ was used to select the four most popular commercial channels for children. In order to attempt to encompass the whole child viewing population, channels were selected from free-to-air terrestrial (ITV England and Wales), free-to-air digital (CITV) and subscription satellite (Nick Junior and Nickelodeon) broadcasting. These channels were recorded during the following five one-week periods:

1. Week beginning Monday 16 October 2006;

2. Week beginning Monday 23 October 2006 (half-term school holiday in England);

3. Week beginning Monday 30 October 2006 (half-term school holiday in Wales);

4. Week beginning Monday 19 December 2006;

5. Week beginning Monday 8 January 2007.

These were selected to allow examination of the influence of school holidays on television advertisements. In each week, recording was carried out on three randomly selected days of the week (two weekdays and a weekend day).

Recording took place during the most popular viewing times for children ${ }^{(24)}$ or until the selected channel ceased broadcasting. Thus, the channels were recorded between 06.30 and 08.30 hours and between 15.30 and 23.00 hours on weekdays; at weekends, recording was carried out between 07.00 and 13.00 hours and 17.00 and 23.00 hours. It should be noted, however, that CITV and Nick Junior ceased broadcasting at 18.00 and 22.00 hours, respectively.

The four channels were recorded on separate DVD recording equipment and were analysed by a single investigator (A.P.) who collated information on the type, content and duration (in seconds) of each advertisement shown. The timing of the advertisements was calculated using the automated digital clock within a computerised DVD player (Version 6, Cyberlink Corporation, 1997-2004). Analysis was conducted using a proforma according to categories and criteria (explained below) agreed with the 
other researchers. Cases lacking immediate clarity were resolved and ratified through discussion with other members of the research team. Of the total $503 \mathrm{~h}$ recorded, $5 \cdot 5 \%(27 \cdot 5 \mathrm{~h})$ were reviewed by a second reviewer. There was $89.5 \%$ agreement between the primary (A.P.) and secondary reviewers (M.M.) in allocation of advertisements to product categories.

Advertisements were categorised as 'food' and 'nonfood'. Since the main focus of the research was television advertising and its impact on oral health, the former category was further subdivided into 'high-sugar foods' (some of which also contain high levels of fat and/or salt) and 'other foods' (which would also include some foods which were high in salt and/or fat, but not sugar). The high-sugar foods category was based on the FSA's classification, i.e. foods containing more than $10 \mathrm{~g}$ sugar/ $100 \mathrm{~g}$ are considered to contain 'a lot of sugar'. The FSA low sugar category (less than $2 \mathrm{~g}$ sugar/100 g) and moderate sugar category (2-9g sugar/100 g) were combined for the purpose of this analysis ${ }^{(26)}$.

Foods included in the high-sugar category were:

1. Dairy sweetened, e.g. yoghurt, milk drinks;

2. Confectionery, e.g. sweets, chocolate;

3. Cereals high in sugar, e.g. Coco Rocks, Coco Pops, cereal bars;

4. Baked goods high in sugar, e.g. cakes, biscuits;

5. Drinks high in sugar, e.g. drinking chocolate, sweetened carbonated beverages.

Foods included in the other foods category were:

1. Dairy unsweetened, e.g. milk, butter, cheese;

2. Cereals low to moderate in sugar, e.g. Weetabix, Oatabix.

In the non-food category, oral health products and healthy living were recorded as distinct from other nonfood advertisements using three categories:

1. Toys, games, fashion, finance, household cleaning products, toiletries, entertainment, etc.;

2. Healthy living, e.g. promoting healthy living/eating;

3. Oral health products, e.g. toothpaste, toothbrushes.

Microsoft ${ }^{\circledR}$ Excel 2003 software package (Microsoft Corporation, Redmond, WA, USA) was employed for data collation and presentation. The Statistical Package for the Social Sciences statistical software package version $12 \cdot 0$ (SPSS Inc., Chicago, IL, USA) was used for analysis. Frequency distributions of the categories of advertisements were compiled and the $\chi^{2}$ test was applied to compare the proportion of viewing times (in seconds) within the high-sugar food categories. A significance level of $P<0.05$ was accepted as statistically significant ${ }^{(27)}$.

\section{Results}

A total of $503 \mathrm{~h}$ of television were recorded, ranging from $92 \mathrm{~h}$ in week 4 to $106 \mathrm{~h}$ each in week 1 and week 5 . The duration of recording by channel was $78 \mathrm{~h}$ for CITV, $134 \mathrm{~h}$ for Nick Junior, $141 \mathrm{~h}$ for ITV and $150 \mathrm{~h}$ for Nickelodeon. Advertising accounted for $15 \%(75.5 \mathrm{~h})$ of this time, equating to 9 min of advertising televised per hour.

The average advertising times for the various product categories were calculated in seconds per hour to account for the differences in recording times between channels and weeks.

Table 1 shows the percentage of total advertising time devoted to each product category. The advertisement of high-sugar products occupied $6.3 \%$ of total advertising time, equating to $38.4 \%$ of the advertising time devoted to food. In contrast, foods low in sugar featured in only $2 \cdot 8 \%$ of the total advertising time; this equates to $17 \cdot 0 \%$ of the advertising time devoted to food. The promotion of healthy living and oral hygiene products accounted for only $1.8 \%$ and $0 \cdot 3 \%$, respectively, of the total advertising time.

Figure 1 illustrates the contribution of the various product sub-categories within the total time devoted to the promotion of high-sugar foods. Cereals high in sugar dominated the advertisements, with $40 \cdot 7 \%$ of high-sugar food advertisements represented by this category $\left(\chi^{2}=6524 \cdot 8, \mathrm{df}=4, P<0 \cdot 001\right)$.

The amount of time (in seconds per hour) devoted to the advertisement of high-sugar foods by channel ranged from $10 \cdot 2$ for Nick Junior, to $31 \cdot 8$ for CITV, $41 \cdot 1$ for ITV and $49 \cdot 6$ for Nickelodeon. Figure 2 focuses on the effect of channel on the advertisement of the different highsugar food product categories; sweetened dairy products made up $82.4 \%$ of advertisements in this category on Nick Junior, a channel aimed at pre-school children, compared with only $9 \cdot 1 \%$ of advertisements on CITV.

Figures 3 and 4 illustrate the effect of the week in which recording took place. Figure 3 shows how the proportion of total advertising time devoted to the three main advertising categories (non-food, high-sugar food and other food) varied by week; the advertising of highsugar products was greatest in week 4 of recording, i.e. the week before Christmas, and reduced in week 5 , two weeks after Christmas $\left(\chi^{2}=69 \cdot 7, \mathrm{df}=8, P<0 \cdot 001\right.$, food category by week weighted by seconds). This trend is likely to be related to the fact that baked sweetened

Table 1 Percentage of total advertising time devoted to each product category: content analysis of children's television advertising with focus on food and oral health, UK, 2006-2007

\begin{tabular}{lrrr}
\hline $\begin{array}{l}\text { Product } \\
\text { advertised }\end{array}$ & Seconds & $\begin{array}{c}\text { Seconds } \\
\text { per hour }\end{array}$ & $\begin{array}{c}\text { \% of total } \\
\text { advertising time }\end{array}$ \\
\hline Non-food* & 221550 & $440 \cdot 0$ & $81 \cdot 5$ \\
Healthy living & 4940 & $9 \cdot 8$ & $1 \cdot 8$ \\
Oral health & 880 & $1 \cdot 7$ & $0 \cdot 3$ \\
High-sugar food & 17120 & $34 \cdot 0$ & $6 \cdot 3$ \\
Low-sugar food & 7560 & $15 \cdot 0$ & $2 \cdot 8$ \\
Other food & 19880 & $39 \cdot 5$ & $7 \cdot 3$ \\
Total & 271930 & $540 \cdot 1$ & \\
\hline
\end{tabular}

*Non-food category excludes Healthy living and Oral health. 


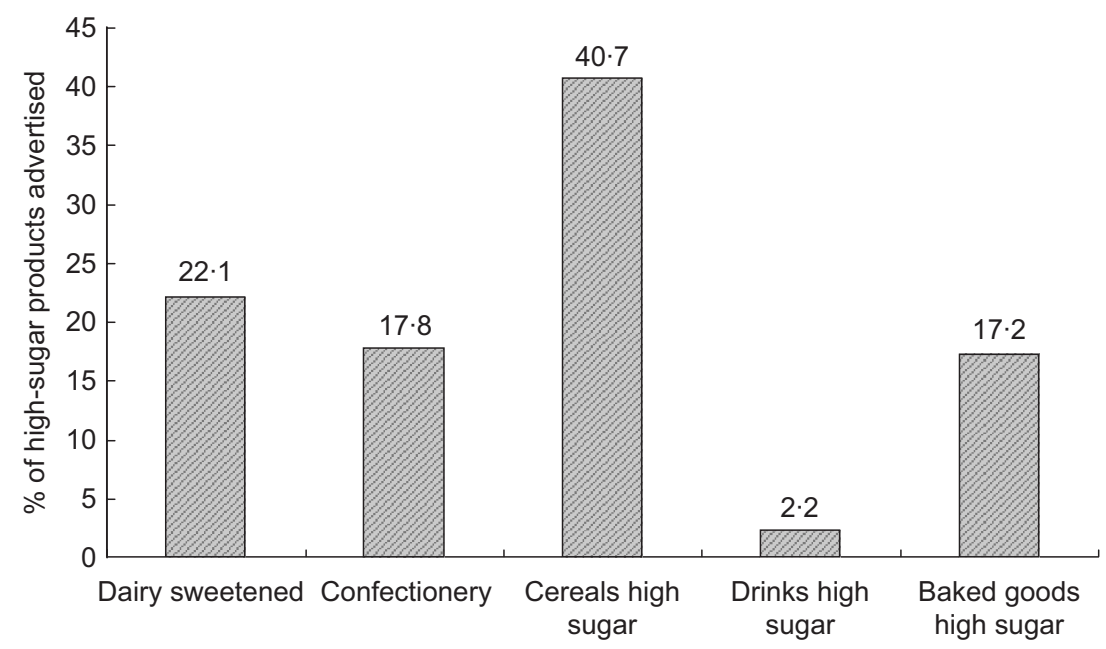

Fig. 1 Percentage of high-sugar food advertising time by product sub-category: content analysis of children's television advertising with focus on food and oral health, UK, 2006-2007. One-sample $\chi^{2}$ test for the difference in proportions of advertising times for product categories, $P<0.001$

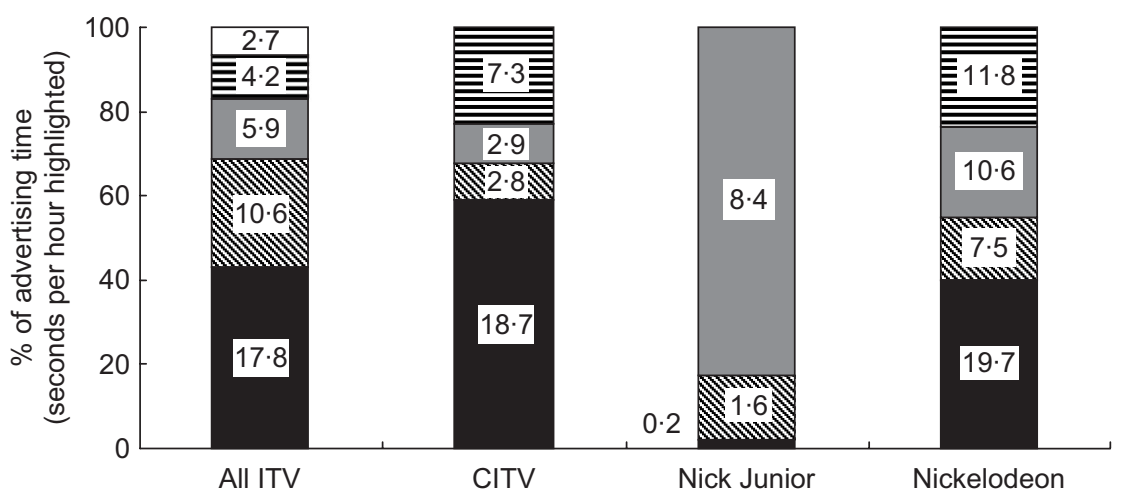

Fig. 2 Proportion of total advertising time devoted to high-sugar sub-categories ( $\square$, sugared cereals; $\mathbb{\mathbb { N }}$, confectionery; $\square$, dairy sweetened; 目, baked sweetened; $\square$, sugary drinks) by channel, with seconds per hour highlighted in bars: content analysis of children's television advertising with focus on food and oral health, UK, 2006-2007

products were advertised most in week 4, accounting for over half of the high-sugar products advertised in that week (Fig. 4).

\section{Discussion}

Previous content analyses of television advertising to children using an oral health perspective ${ }^{(21,28)}$ have considered only the traditional prime viewing times and have disregarded the fact that children watch television outside these hours on an increasing number of television channels ${ }^{(20)}$. In the current study selection of recording times and channels was based on information produced by Ofcom and BARB ${ }^{(22,25)}$. This showed that the peak television viewing time for children in the evening was not during children's prime time television but later. In addition, many children continued to watch long beyond this time.
The present study found that $16 \cdot 4 \%$ of advertising was for food and drink and that $38.4 \%$ of this $(6 \cdot 3 \%$ of all advertising) was for food and drink high in sugar and, therefore, deemed to be potentially cariogenic. In comparison, Rodd and Patel ${ }^{(21)}$ found that $34 \cdot 8 \%$ of advertisements were related to food and drink products, $95 \cdot 3 \%$ of these being deemed potentially cariogenic or erosive to teeth. Likewise, Chestnutt and Ashraf ${ }^{(28)}$ found that a much greater proportion of advertising time $(62.5 \%)$ was devoted to food products, with $73 \cdot 4 \%$ of this being devoted to products deemed potentially detrimental to oral health. The difference between the current study and those reported previously may be due to the changes in advertising policy which have taken place over recent years and differences in study design. The study of Chestnutt and Ashraf ${ }^{(28)}$ in 2002 pre-dates the advertising of food to children debate, which originated in 2003 when the UK Department of Health requested that Ofcom look at the possibility of strengthening the rules on food advertising to children on 


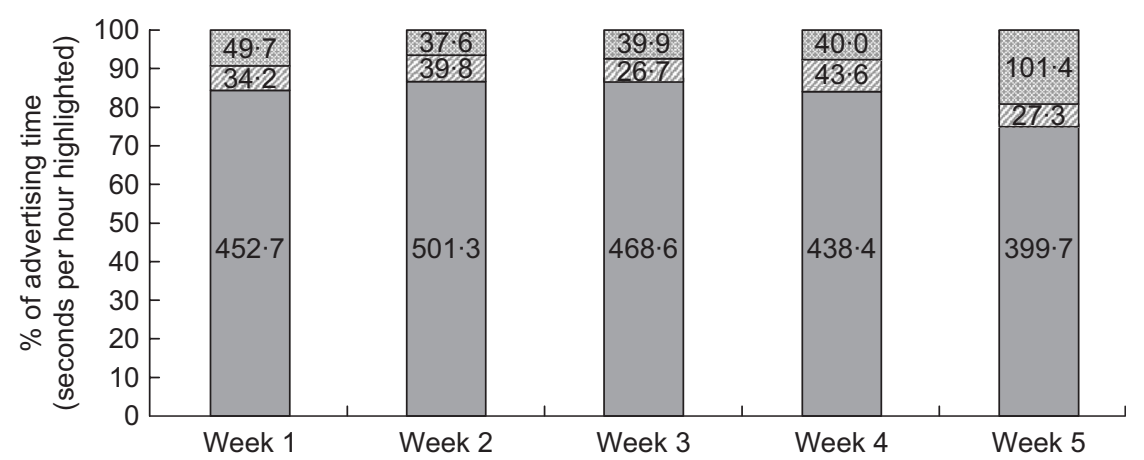

Fig. 3 Proportion of total advertising time devoted to main product categories ( $\square$, non-food; 圂, high-sugar food; $\square$, other food) by week, with seconds per hour highlighted in bars: content analysis of children's television advertising with focus on food and oral health, UK, 2006-2007. Two-sample $\chi^{2}$ test for the difference in proportions of advertising times for product categories by week, $P<0.001$

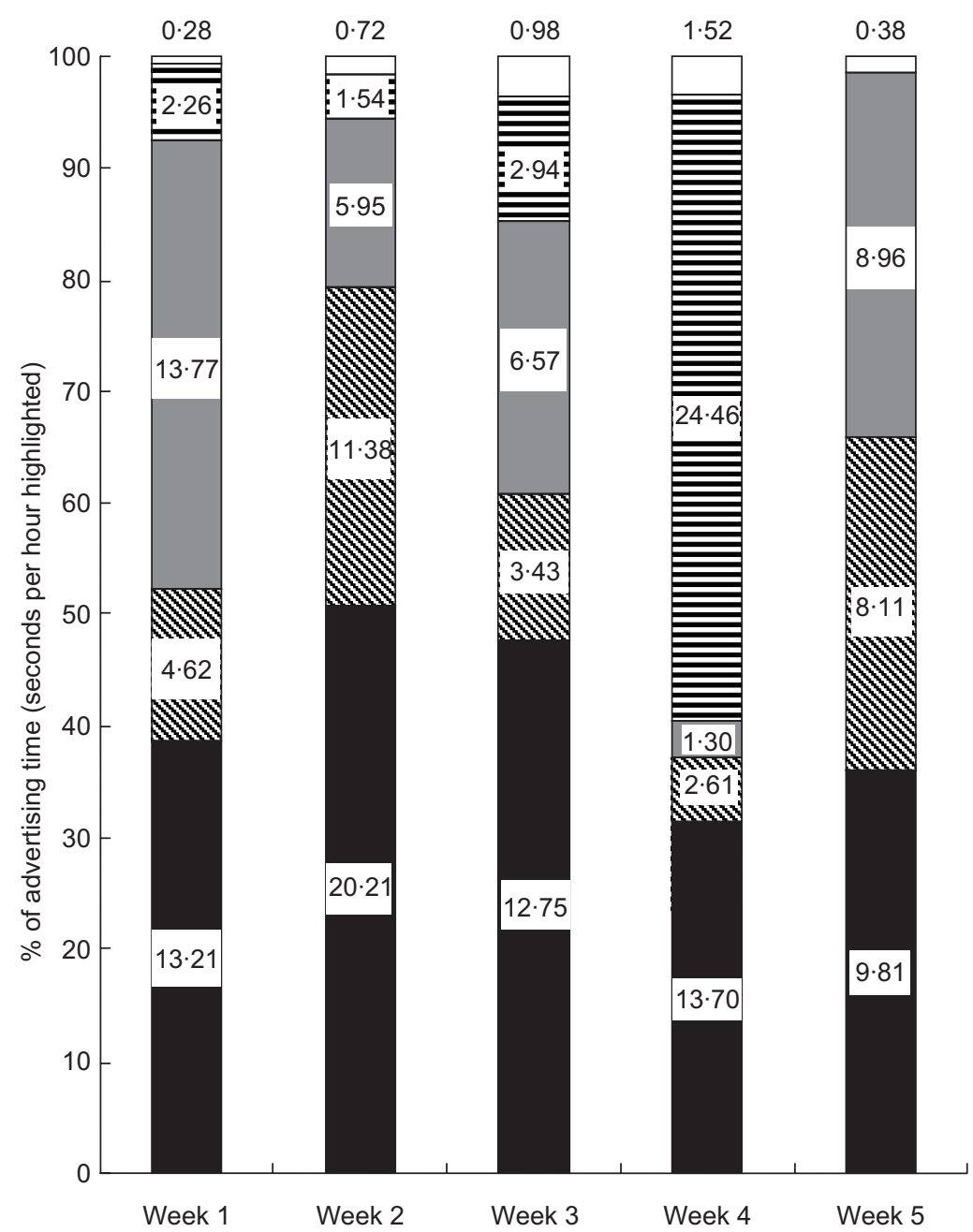

Fig. 4 Proportion of total advertising time devoted to high-sugar sub-categories ( $\square$, sugared cereals; $\mathbb{\mathbb { N }}$, confectionery; $\square$, dairy sweetened; 目, baked sweetened; $\square$, sugary drinks) by week, with seconds per hour highlighted in bars: content analysis of children's television advertising with focus on food and oral health, UK, 2006-2007

television $^{(29)}$. In 2005, during the lengthy Ofcom consultation process, Rodd and Patel ${ }^{(21)}$ published their research on the effects of food advertising on children. The present study was undertaken during the period when the Ofcom regulations concerning both content and scheduling of advertisements were starting to be enforced ${ }^{(30)}$.

In relation to differences in study design, Rodd and Patel $^{(21)}$ and Chestnutt and Ashraf ${ }^{(28)}$ each collected a 
smaller amount of data from only a single television channel over a shorter period of time and during a more restricted period of the day. The reduction in high-sugar food advertising highlighted in the present study compared with previous studies should be interpreted with caution, as it may be an artefact of differences in study design. However, this should not detract from the fact that high-sugar cereals were found to dominate children's food television advertising in the present study.

Prior to commencing the current study, the authors assumed that the majority of advertising time devoted to high-sugar products would be related to confectionery. Chestnutt and Ashraf ${ }^{(28)}$ for example found that $46.6 \%$ of advertisements were for confectionery, $24 \cdot 1 \%$ were for sugared cereals and $16 \cdot 0 \%$ for sugared dairy products. However, the study found that confectionery was only the third most commonly advertised high-sugar food $(17 \cdot 8 \%)$. Sugared cereal was the most commonly advertised $(40.7 \%)$, followed by sweetened dairy products (22.1\%; Fig. 1) which appear to be targeted at the younger audience associated with Nick Junior (Fig. 2). Interestingly, Rodd and Patel ${ }^{(21)}$ also found that sugared cereals were the most commonly advertised high-sugar products. However, the amount advertised equated to just over a quarter $(26 \cdot 3 \%)$ of all advertisements for high-sugar products.

This movement away from confectionery advertisement to high-sugar-containing cereal foods and sweetened dairy products has been noted as a possible future public health problem ${ }^{(31)}$. The reasons for this concern are that eating breakfast is a mainstay of public health nutrition advice, and both cereals and dairy products are promoted as constituents of a healthy diet ${ }^{(26)}$. However, the majority of sweetened breakfast cereals contain over $30 \%$ sugar while sweetened dairy products contain around $15 \%$, both in excess of the FSA high sugar category. Advertising which concentrates on these foods could lead to confusion among consumers, particularly children, and encourage consumption of foods perceived as healthy which are in fact high in sugar, with negative health consequences in terms of oral health and obesity.

Data from the present study would therefore suggest that, even before the restriction recently imposed by Ofcom, television advertising was not targeting confectionery and high-sugar products as heavily as had previously been reported ${ }^{(28)}$. In addition, there appears to have been a shift in the type of high-sugar products advertised, with sugared cereals and sugared dairy products being promoted in preference to confectionery. These observations may be attributable to: (i) the impending changes in legislation affecting the television advertising of HFSS foods to children; (ii) variation in the definition of food categories (for example, biscuit could be placed in confectionery or high-sugar baked foods); or (iii) changes in advertising over the years, with the proliferation of channels providing marketing companies with more choice.
Nickelodeon (the selected subscription satellite children's channel) devoted the largest amount of broadcasting time to advertising ( $10 \mathrm{~min} 10 \mathrm{~s}$ per hour). This channel also devoted the majority of its advertising time to non-food (mainly toys and games) and high-sugar products; sugared cereals, sweetened dairy and sugary baked products received more advertising time than on any other channel. Nickelodeon tends to target an older audience than Nick Junior and CITV. It is likely that advertisers utilise Nickelodeon to reach children who receive more pocket money and have more influence on product purchase ${ }^{(32)}$.

ITV (England and Wales) advertised the largest proportion of other food products but also devoted more advertising time to confectionery and sugary drinks than any other channel. Although Nick Junior promoted highsugar foods least, in excess of $80 \%$ of this advertising was related to sweetened dairy products (Fig. 2). As Nick Junior is aimed at younger children the advertisers are manipulating parents by promoting dairy foods, an important food group, without referring to their high sugar content. On the positive side, a small proportion of Nickelodeon and Nick Junior's advertising time was devoted to Nicktrition, which teaches children about eating healthy foods and taking regular exercise.

Chestnutt and Ashraf ${ }^{(28)}$ included a range of months in their study in order to reflect any seasonal variation in advertising but, interestingly, made no reference to there being any effect of this parameter in their publication. The present study found there to be a degree of variation in the amount of advertising devoted to confectionery and other high-sugar products when comparing school holiday and non-holiday periods. Most time devoted to high-sugar product advertising occurred in week 4 , the week before Christmas. Surprisingly, confectionery was advertised the least in this week, with baked sugary products receiving the most attention. This may be due to marketing companies working on the assumption that most non-perishable food purchases, such as confectionery, would have been made early and would therefore not require further promotion. In contrast, the largest proportion of advertising time devoted to confectionery and sugared cereals occurred in week 2, English schools' half term. It should be noted, however, that ITV England was recorded in this week, when ITV Wales was used for all other weeks. Any bias thereby introduced should, however, be minimal: given that virtually all the products advertised are marketed by national and international corporations, it is likely that those broadcast in the different ITV regions are not dissimilar. This part of the study would have benefited from being further extended to include other holiday influences such as Easter (with the sale of confectionery) and the summer (with the sale of sugary soft drinks and sweetened dairy products such as frozen desserts including ice cream). A more detailed comparison of the advertising patterns of 
different ITV channels could also have been made. Given the ongoing changes to children's television advertising $^{(24)}$, however, this is now impossible. Nevertheless, the current study is of value as a baseline comparator.

It is important to be aware that confectionery and other leading food companies are now turning to alternative forms of advertising. For example, children are keen consumer cyber-surfers with over half of 7-16-year-olds (57\%) having bought on the Internet ${ }^{(32)}$. By finding alternative marketing methods such as the Internet, companies will continue to target children directly even after the implementation of Ofcom's new legislations. Other popular marketing methods include children's films and sporting events such as the World Cup. Increasingly, advertisements are also turning to parents, making HFSs foods such as sweetened cereals and dairy products seem healthy options for their children. Marketing tricks such as film freebies, websites, text messages, day trips, sponsored hotel suites, classroom schoolbooks, viral marketing, football frenzy, competitions, joining clubs, gifts and giveaways, funky formats, healthy hints, on-pack offers, coupon collecting, cartoon characters and using health claims to promote products to parents are all tactics which have been used to promote confectionery, high-sugar foods and 'junk' food to children ${ }^{(33)}$.

The authors wish to emphasise that, while the present study focused on oral health, the implications for health in general, particularly with the year-on-year increase in childhood obesity, are clear ${ }^{(34)}$.

\section{Conclusion}

Our research indicates that there has been a shift in advertising away from confectionery and towards foods that appear healthier but actually contain large amounts of hidden sugars; for example, high-sugar breakfast cereals and sweetened dairy products. This shift occurred even before the introduction of recent legislation. These findings are of relevance to the dental profession in the prevention of dental caries and wider public health professionals in relation to both general health and obesity.

\section{Acknowledgements}

There are no conflicts of interest associated with this research. The research was funded by Cardiff University School of Dentistry. M.M. conceived the idea, was project supervisor and primary author; A.P. conducted the research and was secondary author; K.S., R.F. and L.H. contributed to the theoretical design of the research and contributed to writing the paper.

Acknowledgements: The authors wish to express their sincere thanks to Dr Richard Morgan, Mr Rikin Patel and Mr Antony Phillips for their help with recording.

\section{References}

1. Pitts NB, Boyles J, Nugent ZJ, Thomas N \& Pine C (2006) The dental caries experience of 11-year-old children in Great Britain. Surveys co-ordinated by the British Association for the Study of Community Dentistry in 2004/2005. Community Dent Health 23, 44-57.

2. Pitts NB, Boyles J, Nugent ZJ, Thomas N \& Pine C (2007) The dental caries experience of 5-year-old children in Great Britain (2005/6). Surveys co-ordinated by the British Association for the Study of Community Dentistry. Community Dent Health 24, 59-63.

3. Jebb SA, Rennie KL \& Cole TJ (2004) Prevalence of overweight and obesity among young people in Great Britain. Public Health Nutr 7, 461-465.

4. James PT, Leach R, Kalamara E \& Shayeghi M (2001) The worldwide obesity epidemic. Obes Res 9, 228S-233S.

5. Kantovitz KR, Pascon FM, Rontani RM \& Gavião MB (2006) Obesity and dental caries - a systematic review. Oral Health Prev Dent 4, 137-144.

6. Locker D (2000) Deprivation and oral health: a review. Community Dent Oral Epidemiol 28, 161-169.

7. Armstrong J, Dorosty AR \& Reilly JJ (2003) Coexistence of social inequalities in undernutrition and obesity in preschool children; population based cross-sectional study. Arch Dis Child 88, 671-675.

8. Dibsdall LA, Lambert N, Bobbin RF \& Frewer LJ (2003) Low-income consumers' attitudes and behaviour towards access, availability and motivation to eat fruit and vegetables. Public Health Nutr 6, 159-168.

9. Vanhala M, Vanhala P, Kumpusalo E, Halonen P \& Takala J (1998) Relation between obesity from childhood to adulthood and the metabolic syndrome: population based study. BMJ 317, 319.

10. Rugg-Gunn AJ (1993) Nutrition and Dental Health. Oxford: Oxford University Press.

11. Food Standards Agency (2007) Advertising to children. Key facts. http://www.food.gov.uk/healthiereating/advertising tochildren/nutlab/nutrientprofilefacts (accessed March 2008).

12. Wardle J (2007) Eating behaviour and obesity. Obes Rev $\mathbf{8}$, Suppl. 1, 73-75.

13. Lobstein T \& Dibb S (2005) Evidence of a possible link between obesogenic food advertising and child overweight. Obes Rev 6, 203-208.

14. Austin MJ \& Reed ML (1999) Targeting children online: Internet advertising ethics issues. J Consumer Marketing 16, 590-602.

15. Hastings G, Stead M, McDermott L, Forsyth A, MacKintosh AM, Rayner M, Godfrey C, Caraher M \& Angus K (2003) Review of Research on the Effects of Food Promotion to Children. Final Report. Glasgow: Centre for Social Marketing.

16. Halford JC, Boyland EJ, Hughes GM, Stacey L, McKean S \& Dovey TM (2007) Beyond-brand effect of television food advertisements on food choice in children: the effects of weight status. Public Health Nutr (Epublication ahead of print version).

17. Valkenburg PM (2000) Media and youth consumerism. J Adolesc Health 27, Suppl. 2, 52-56.

18. Livingstone S (2004) A commentary on the research evidence regarding the effects of food promotion on children. Prepared for the Research Department of the Office of Communications (OFCOM). http://www.ofcom. org.uk/research/tv/reports/food_ads/appendix1.pdf (accessed March 2008).

19. Signorielli N \& Lears M (1992) Television and children's conceptions of nutrition: unhealthy messages. Health Commun 4, 245-257.

20. Ofcom (2007) The future of children's television programming. http://www.ofcom.org.uk/consult/condocs/kidstv/ kidstvresearch.pdf (accessed March 2008). 
21. Rodd HD \& Patel V (2005) Content analysis of children's television advertising in relation to dental health. Br Dent J 199, 710-712.

22. OFCOM (2004) BARB TV Viewing Data 2003. http:// www.ofcom.org.uk/research/tv/reports/food_ads/appendix3. pdf (accessed June 2008).

23. Lawlor DA, Ebrahim S \& Davey Smith G (2002) Socioeconomic position in childhood and adulthood and insulin resistance: cross sectional survey using data from British women's heart and health study. BMJ 325, 805-807.

24. Ofcom (2007) Television advertising of food and drink products to children. Final statement. http://www.ofcom. org.uk/consult/condocs/foodads_new/statement/statement. pdf (accessed March 2007).

25. BARB (2006) Weekly Viewing Summary for 24 September 06. http://www.barb.co.uk/viewingsummary/weekreports.cfm? report $=$ multichannel\&requesttimeout $=500 \&$ flag $=$ viewing summary.htm (accessed 11 October 2006).

26. Food Standards Agency (2005) Eat Well Be Well. Your guide to healthy eating. http://www.breakfastcereal.org/ eatwell_leaflet.pdf (accessed March 2008).

27. Bland JM (2000) An Introduction to Medical Statistics, 3rd ed. Oxford: Oxford University Press.
28. Chestnutt IG \& Ashraf FJ (2002) Television advertising of foodstuffs potentially detrimental to oral health - a content analysis and comparison of children's and primetime broadcasts. Community Dent Health 19, 86-89.

29. Advertising Standards Authority (2008) The Advertising of Food to Children. http://www.asa.org.uk/NR/rdonlyres/ F60412F1-6C6E-40B0-9A82-91672BA4B840/0/Foodheaded. pdf (accessed March 2008).

30. Caraher M, Landon J \& Dalmeny K (2006) Television advertising and children: lessons from policy development. Public Health Nutr 9, 596-605.

31. Yngve A (2007) Overview. In Public Health Nutrition: From Principles to Practice, pp. 1-3 [M Lawrence and T Worsley, editors]. Milton Keynes: Open University Press.

32. Halifax (2006) Annual Halifax Pocket Money Survey. http:// www.hbosplc.com/media/includes/15_\%2004_\%2006_\%20 Pocket_\%20Money_\%20Survey_\%202006\%20_\%20National.doc (accessed March 2007).

33. Consumers Association (2006) Food Fables. Exploring Industry Myths on Responsible Food Marketing to Kids. Campaign Report. London: Consumers Association.

34. National Audit Office (2006) Tackling Childhood Obesity First Steps. http://www.nao.org.uk/publications/nao_reports/ 05-06/0506801.pdf (accessed July 2007). 